We thank Ray Flux of CivilEyes for advice and for supplying, delivering, and downloading the survey units; the postgraduate centre managers and medical personnel officers for ensuring a good response rate; the trainees; and the consultant trainers.

Contributors: EP conceived the project, piloted the first version of the questionnaire, analysed the results, and drafted the paper; she will act as guarantor for the paper. MA project managed the second survey, entered the postal data, and checked the analysis. GC and SH contributed to the design of the project, the development of the questionnaire, and the writing of the final manuscript.

Funding: None.

Competing interests: None declared.

1 Working group on specialist medical training. Hospital doctors: training for the future. London: Department of Health, 1993.

2 Department of Health. A guide to specialist registrar training. London: HMSO, 1995

3 Milligan DWA, Hall D. Implications of the Calman report on child health and paediatrics. Arch Dis Child 1996;74:260-3.

Hunter S, McLaren P. Specialist medical training and the Calman report. BMJ 1993;306:1281-2.

5 Collins M, Ryan R. Single grade specialist training in otolaryngology -a survey of attitudes among present and recent trainees. J Laryngol Otol $1994 ; 108: 291-3$

6 Bayley TJ. Specialist training. Med Educ 1995;29(suppl 1):95-6.
7 Bates T. Curricular training and the new deal. Ann R Coll Surg Engl 1996;78(suppl):61-2.

8 NHS Management Executive. Junior doctors: the new deal. London: Department of Health, 1991.

9 Charlton B. Service implications of the Calman report. BMJ 1993;307: 338-9.

10 Mather HM, Elkeles RS. Attitude of consultant physicians to Calman proposals: a questionnaire survey. BMJ 1995;311:1060-2.

11 Dempsey GA, Skinner A. Attitudes of consultant anaesthetists to the Calman proposals: a questionnaire survey. Anaesthesia 1997;52:181-2.

12 Johnson JN. Survey illustrates misconception of the Calman proposals. BMJ 1995;311:1298.

13 Temple JG. Attitudes of consultant physicians to Calman proposals. BMJ 1995;311:1574.

14 Paice E, Pietroni M, Tinker J. Future training of hospital doctors. Br J Hosp Med 1993;50:199-201.

15 Paice E, West G. Talking to the lost tribes: senior house officer training in North-East Thames. Br J Hosp Med 1994;51:123-7.

16 General Medical Council. The new doctor. London: GMC, 1997.

17 Barber P. The colleges, Calman and the new deal. Lancet 1997;350:974.

18 Hobbs KEF. Specialist training in the UK. Lancet 1997:350:1851.

19 Paice E, West G, Cooper R, Orton V, Scotland A. Senior house officer training: is it getting better? BMJ 1997;314:719-20.

20 Allen I, Herzberg J, Hale R, Paice E. Stress in consultants in North Thames. London: Policy Studies Institute, 1999.

21 Anderson J. The effect of Calman reforms on recruitment, training and service provision. Arch Dis Child 1999;80:485-7.

(Accepted 11 January 2000)

\title{
Recognition of television images as a developmental milestone in young children: observational study
}

B W Lloyd, K Brodie

\begin{abstract}
Children's
Department, North Middlesex Hospital, London N18 1QX

B W Lloyd

consultant

paediatrician

K Brodie

paediatric senior

registrar

Correspondence to:

Dr Lloyd, Child

Health, Royal Free

Hospital, London

NW3 2QG
\end{abstract}

blloyd@rfhsm.ac.uk

BMJ 2000;320:836-8

\begin{abstract}
Objectives To determine the age at which children with apparently normal development can recognise the television image of a cat, dog, or baby.

Design Observational study.

Setting District general hospital in north London. Subjects 797 children with apparently normal development aged between 8 and 23 months and 26 children with Down's syndrome aged 18 months. Outcome measures Whether or not the child recognised the television image of a cat, dog, or baby by naming, imitating, or pointing at the image. Results By 18 months of age 96\% (95\% confidence interval $94 \%$ to $98 \%$ ) of normal children recognised the television image of a cat, dog, or baby compared with 5 of $26(19 \%)$ children with Down's syndrome.

Conclusion Recognition of the television image of a cat, dog, or baby is a simple milestone, which may help in the developmental assessment of young children.
\end{abstract}

\section{Introduction}

A child who is slow to talk at 18-24 months of age is likely to be normal but can cause concern about learning disabilities or a severe language disorder. It is sometimes difficult to assess the development of such young children, and there are few relevant and validated milestones in this age group. A pilot investigation led us to hypothesise that determining how much interest children show in television images might provide helpful information about children's development.

\section{Methods}

One of us (BL) approached the parents of children who were either patients or siblings of patients at North Middlesex Hospital in north London. We excluded children who were preterm, who had known developmental problems, or whose parents did not speak English or own a television.

We first asked the parents "Does your child recognise the picture of a cat, dog, or baby on the television screen?" If the response was "yes," we asked "How do you know?"

We concluded that the child recognised the television image if he or she named, imitated, or pointed at it. Becoming excited or patting the screen was not considered sufficient evidence.

The same questions were used by $\mathrm{KB}$ when interviewing the parents of 18 month old children with Down's syndrome by telephone. These families were identified by the Family Fund, a national organisation that supports the families of children with disabilities.

\section{Results}

We interviewed the parents of 797 children of apparently normal development aged between 8 and 23 months. At each month of age we interviewed the parents of between 36 and 61 children (mean 49.8). In addition, we interviewed 26 parents of children with Down's syndrome aged 18 months.

A statistical model describing the percentage of children at each age who recognised a television image was fitted using logistic regression (figure).

By 18 months of age $96 \%$ (95\% confidence interval $94 \%$ to $98 \%$ ) of normal children were reported to 


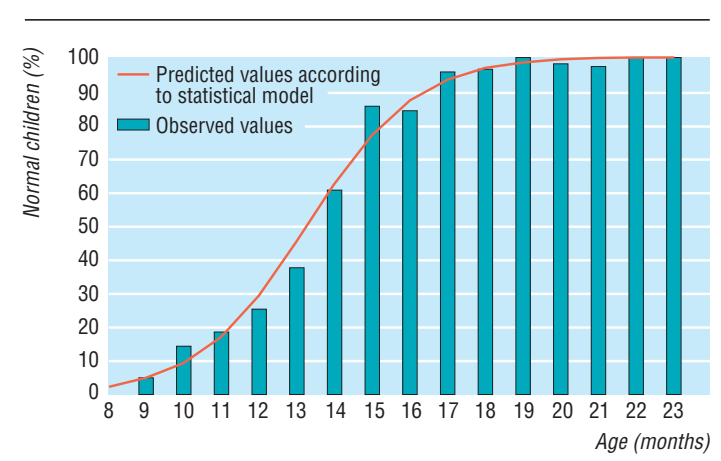

Percentage of normal children recognising television images of cat, dog, or baby at ages between 8 and 23 months; curve fitted using logistic regression

recognise the television image of a cat, dog, or baby (figure) compared with 5 of $26(19 \%)$ of the 18 month old children with Down's syndrome.

\section{Discussion}

\section{Findings and shortcomings}

Nearly all (96\%) of the normal children were reported to recognise the television image of a cat, dog, or baby by 18 months of age. Some parents may have exaggerated their child's abilities, but the pattern of responses (figure) supports the view that our cut off point of 18 months is meaningful. Our study population seems likely to be broadly representative of British children. We do not think our findings were distorted by the possible inclusion of a few children with unrecognised developmental problems.

We did not question the parents in enough detail to be absolutely sure that the child's pointing was designed to involve the parent (protodeclarative) rather than being a form of instruction (protoimperative). Assuming the pointing was protodeclarative, our milestone is a test of both understanding (does the child recognise the image?) and "joint attention behaviours" (does the child want to share their interest?). The first of these skills is impaired in a child with learning difficulties and the second of these is impaired in a child with autism.

Reynell described the development of the symbolic understanding necessary for the development of language. ${ }^{1}$ As a child becomes older he or she is able to recognise increasingly abstract representations of an object, including increasingly abstract pictures. The television image of an object is more abstract than pictures in books designed for very young children. Nevertheless, our milestone is not a test of symbolic understanding.

\section{Previous work}

Review of the published literature on pointing shows some disagreement about when children recognise images other than those seen on television. According to the most recent manual for use with Griffiths testing, a child "enjoys picture book" by 15 months of age and "likes adult to show book" from 17 months of age. ${ }^{2}$ Sheridan reported that at 12 months of age a child "points with index finger at objects of interest" and "shows interest in pictures." At 15 months of age he or she "looks with interest at coloured pictures in book and pats page." At 18 months of age he or she enjoys simple picture books "often recognising and putting index finger on boldly coloured items on page." In contrast, Reynell reported that at about 20-24 months of age a child of normal development is capable of recognising "clear coloured pictures." Baron-Cohen et al reported that children aged 18 months were likely to be diagnosed later as being autistic if they failed three items of a developmental assessment: protodeclarative pointing, gaze monitoring, and pretend play.

\section{Usefulness of milestone}

When a child with normal vision is slow to pass our milestone, three main developmental disorders should be considered: learning disabilities, a pure language disorder, and autism. The range of normality is such that, as with any milestone, some children of normal development will fail to pass it on time. Equally, some children with learning or communication problems will not be detected by the use of our milestone, as shown by our findings in children with Down's syndrome.

Formal testing systems such as the Griffiths and Bayley tests require training and special equipment. ${ }^{15}$ The Denver developmental assessment test is simpler to use. ${ }^{6}$ In this test, however, the only test item that is relevant to language development, that does not involve an ability to talk, and that should reliably be achieved before 24 months of age, is the reported ability to help about the house.

We do not fear that asking about our milestone could encourage excessive television viewing. Indeed, we usually couple inquiry about this milestone with suggestions about limiting television viewing.

We consider that our milestone is a useful part of the developmental assessment of children aged 15-24 months. Unlike many milestones, ours is supported by information about a large number of childrenroughly twice the number tested over the same age range during the recent revision of the Griffiths's scale. ${ }^{1}$

Our milestone needs neither special equipment nor special training. This makes it particularly useful for general practitioners and health visitors.

We thank Mrs Dot Lawton (Social Policy Research Unit) who, acting on behalf of the Family Fund, put us in touch with the families of children with Down's syndrome, and Dr Hilary Cass and Dr Dominic Croft for helpful suggestions on an earlier draft of the manuscript.

\section{What is already known on this topic}

Few simple and validated milestones exist to help assess the development of children under 2 years old who do not talk

\section{What this study adds}

By 18 months of age $96 \%$ of children of normal development were reported by their parents to show that they recognised the television image of a cat, dog, or baby by naming, imitating, or pointing at the image 
Contributors: BL conceived the study, collected data, and contributed to the writing of the paper. KB collected data and contributed to the writing of the paper. $\mathrm{BL}$ will act as guarantor for the paper.

Funding: None.

Competing interests: None declared.

1 Reynell J. Language development and assessment. Lancaster: MTP, 1980.

2 Huntley M. The Griffiths mental development scales. From birth to 2 years. High Wycombe: Association for Research in Infant and Child Development, 1996.
3 Sheridan MD. From birth to five years. Children's developmental progress. Slough, Middlesex: National Foundation for Educational Research, 1997.

4 Baron-Cohen S, Cox A, Baird G, Swettenham J, Nightingale N, Morgan $\mathrm{K}$, et al. Psychological markers in the detection of autism in infancy in a large population. Br J Psychiatry 1996;168:158-63.

5 Bayley N. Bayley scales of infant development, 2nd ed. San Antonio: Harcourt Brace, 1993.

6 Frankenburg WK, Dodds J, Archer P, Shapiro H, Bresnick B. The Denver II: a major revision and restandardisation of the Denver developmental screening test. Pediatrics 1992;89:91-7.

\title{
Waiting times for cancer patients in England after general practitioners' referrals: retrospective national survey
}

\author{
Peter Spurgeon, Fred Barwell, David Kerr
}

\section{雨}

This paper was first posted on www.bmj.com on 13 March 2000

Health Services Management Centre, School of Public Policy, University of Birmingham, Park House, Birmingham B15 2RT

Peter Spurgeon professor of health services management Fred Barwell honorary research fellow

CRC Institute for Cancer Studies, Medical School, University of Birmingham, Birmingham B15 2TJ

David Kerr professor of clinical oncology

Correspondence to: P Spurgeon p.spurgeon@bham ac.uk

BMJ 2000;320:838-9
Britain fares rather badly in international comparisons of cancer patients' survival rates. Relative survival rates in England and Wales ${ }^{1}$ are generally lower than in Europe, ${ }^{2}$ which in turn are lower than rates in the United States. ${ }^{3}$ The differences between England and Wales and the rest of Western Europe in survival rates for colon cancer and female breast cancer arise primarily in the first six months after diagnosis, suggesting that these differences may relate to later presentation or delays in treatment for British patients.

Given this background, the government has pledged to "end waiting times for cancer surgery, thereby helping thousands of women waiting for breast cancer treatment." The assumption is that reduced waiting times will lead to more rapid diagnosis, earlier instigation of care, and reduced psychological morbidity. Indeed, the NHS has been asked to set a target of two weeks from referral by a general practitioner to first hospital outpatient appointment for all suspected cases of cancer.

In order to investigate the delays that British cancer patients face, we undertook a retrospective survey of patients with newly diagnosed cancer in October 1997.

\section{Subjects, methods, and results}

We invited all English acute hospital trusts (whether cancer centres or units) to submit relevant information on all new patients with a cancer diagnosis confirmed during October 1997. The data were collected during April and May 1998, allowing a tracking period of up to six months after diagnosis. We measured how long the patients were required to wait from their initial referral by their general practitioner for an outpatient appointment, for their first definitive treatment (when appropriate), and for any subsequent treatment.

Data returns were made by $218(98 \%)$ of the 223 trusts, representing 13454 patients. A greater proportion of patients who had been urgently referred by their general practitioner were seen within two weeks compared with those who were non-urgent referrals. However, the results clearly showed that there was substantial variation in patients' waiting times according to tumour type, whether the initial referral was coded urgent, and the region where treatment was undertaken. The table shows that waiting times for urgent appointments were significantly less than the waiting times for non-urgent appointments: this was so for all 10 types of cancer and for time from general practitioner referral to first definitive treatment as well as for time from referral to outpatient appointment.

Waiting times for cancer patients in England, from general practitioner referral to first outpatient appointment and to first definitive treatment (excluding referrals not by general practitioner)

\begin{tabular}{|c|c|c|c|c|}
\hline \multirow[b]{2}{*}{$\begin{array}{l}\text { Type of cancer } \\
\text { and urgency of } \\
\text { referral }\end{array}$} & \multicolumn{2}{|c|}{$\begin{array}{l}\text { Time to first outpatient } \\
\text { appointment (days) }\end{array}$} & \multicolumn{2}{|c|}{$\begin{array}{l}\text { Time to first definitive } \\
\text { treatment (days) }\end{array}$} \\
\hline & $\begin{array}{c}\text { Median } \\
\text { (interquartile } \\
\text { range) }\end{array}$ & $\begin{array}{c}\text { When } 90 \% \\
\text { of patients } \\
\text { seen }\end{array}$ & $\begin{array}{c}\text { Median } \\
\text { (interquartile } \\
\text { range) }\end{array}$ & $\begin{array}{l}\text { When } \mathbf{9 0} \% \\
\text { of patients } \\
\text { seen }\end{array}$ \\
\hline \multicolumn{5}{|l|}{ Breast $(n=1517)$ : } \\
\hline Urgent & $9(4-15)$ & 22 & $27(15-41)$ & 62 \\
\hline Non-urgent & $14(8-21)$ & 29 & $35(21-57)$ & 90 \\
\hline \multicolumn{5}{|c|}{ Colorectal $(n=1023)$ : } \\
\hline Urgent & $13(6-21)$ & 35 & $39(21-64)$ & 95 \\
\hline Non-urgent & $27(16-43)$ & 60 & $72(44-104)$ & 147 \\
\hline \multicolumn{5}{|l|}{ Lung ( $n=767)$ : } \\
\hline Urgent & $7(3-13)$ & 21 & $39(21-61)$ & 91 \\
\hline Non-urgent & $12(7-22)$ & 33 & $47(28-77)$ & 112 \\
\hline \multicolumn{5}{|l|}{ Ovary $(n=189)$ : } \\
\hline Urgent & $6(1-14)$ & 23 & $21(14-40)$ & 64 \\
\hline Non-urgent & $24(7-32)$ & 39 & $45(18-77)$ & 116 \\
\hline \multicolumn{5}{|l|}{ Cervix $(n=321)$ : } \\
\hline Urgent & $22(10-34)$ & 58 & $46(28-79)$ & 123 \\
\hline Non-urgent & $41(27-65)$ & 93 & $75(44-119)$ & 181 \\
\hline \multicolumn{5}{|l|}{ Uterus $(n=223)$ : } \\
\hline Urgent & $19(9-29)$ & 39 & $47(24-83)$ & 114 \\
\hline Non-urgent & $29(19-41)$ & 55 & $73(50-122)$ & 163 \\
\hline \multicolumn{5}{|l|}{ Prostate $(n=677)$ : } \\
\hline Urgent & $19(9-29)$ & 44 & $53(26-91)$ & 143 \\
\hline Non-urgent & $41(23-56)$ & 77 & $111(64-183)$ & 292 \\
\hline \multicolumn{5}{|l|}{ Bladder $(n=627)$ : } \\
\hline Urgent & $20(7-32)$ & 48 & $57(28-84)$ & 124 \\
\hline Non-urgent & $33(21-57)$ & 70 & $82(56-119)$ & 178 \\
\hline \multicolumn{5}{|c|}{ Stomach $(n=241)$ : } \\
\hline Urgent & $10(4-22)$ & 36 & $42(21-73)$ & 112 \\
\hline Non-urgent & $27(18-50)$ & 70 & $75(36-100)$ & 150 \\
\hline \multicolumn{5}{|c|}{ Oesophagus $(n=249)$ : } \\
\hline Urgent & $11(5-21)$ & 33 & $44(24-63)$ & 85 \\
\hline Non-urgent & $24(13-35)$ & 57 & $65(37-112)$ & 154 \\
\hline
\end{tabular}

